Klinik Araştırma/Clinical Research

\title{
Retinal ven dal tıkanıklığına bağlı maküler ödemde intravitreal triamsinolon ve grid la- zer fotokoagulasyon kombine tedavisi
}

Combined treatment of intravitreal triamcinolone enjection and grid laser photocoagulation in eyes with macular edema after branch retinal vein occlusion

Selim Demir*, Gülhan Sarıydın, Gülçin Kazaz, Ebru Cömert, Yüksel Süllü,

Ondokuz Mayıs Üniversitesi, Tıp Fakültesi, Göz Hastalıkları Anabilim Dalı, Samsun

\begin{tabular}{|c|c|}
\hline МАK & GÍLERİ \\
\hline Makal & \\
\hline Geliş & $06 / 08 / 2010$ \\
\hline Kabul & $13 / 10 / 2010$ \\
\hline *Yazış & \\
\hline Selim & \\
\hline İlyaskc் & nice Sokak No:10 Yilmaz \\
\hline $\begin{array}{l}\text { Apt. K } \\
\text { e-posta }\end{array}$ & $\begin{array}{l}\text { msun } \\
\text { demir@mynet.com }\end{array}$ \\
\hline
\end{tabular}

\section{Anahtar Kelimeler:}

Retinal Ven Dal Tıkanıklığı

Maküla Ödemi

İntravitreal Triamsinolon

Grid Lazer Fotokoagülasyon

Tedavi

Görme Kaybı

\section{Key Words :}

Branch Retinal Vein Occlusion

Macular Edema

Intravitreal Triamcinolone

Grid Laser Photocoagulation

Treatment

Visual Loss
ÖZET

Retinal ven tıkanıklıkları, diyabetik retinopatiden sonra en sık görülen retinal vasküler hastalıktır. Bu çalışmamızda retinal ven dal tıkanıklığı (RVDT) nedenli maküler ödem gelişen hastaların tedavisinde intravitreal steroid ve grid lazer fotokoagülasyonun etkisinin değerlendirilmesi amaçlanmıştır. Bu amaçla kliniğimizde Ocak 2007 - Şubat 2009 tarihleri arasında RVDT bağlı maküla ödemi nedeniyle intravitreal triamsinolon asetonid enjeksiyonu ve grid lazer fotokoagülasyon yapılan hastalar geriye dönük olarak değerlendirildi. Hastaların fundus floresein anjiyografi ve optik koherens tomografi ile maküler ödem varlığ teyid edildi. İntravitreal $0,1 \mathrm{~mL}$ (4 $\mathrm{mg}$ ) triamsinolon asetonid enjeksiyonundan 1 ay sonra grid lazer fotokoagülasyon uygulandı. Olguların Snellen eşeli ile en iyi düzeltilmiş görme keskinliği, ön ve arka segment biyomikroskop muayenesi ve intraoküler tansiyon ölçümü yapıldı. Tedavi yapılan 11'i kadın 3'ü erkek 14 hastanın yaş ortalaması 56,3 $\pm 7,3$ idi. Olguların 8 'inde (\%57) üst temporal, 6'sında (\%43) alt temporal ven dal tıkanıklığı vardı. Tedavi öncesine kıyasla görme keskinliği 3. ayda \%43 ve 6 . ayda $\% 57$ olguda bir sıra ve üzerinde arttı. Sadece bir (\%7) olguda takip süresince görme düzeyi bir sıra azaldı. Olguların \%35'ine 6 ay sonunda görme keskinliği sabit kaldı. Tedavi sonrası 6 aylık takipte olguların 3'ünde (\%21) glokom, 1'inde (\%7) katarakt gelişti. Sonuç olarak, retinal ven dal tıkanıklığına bağlı maküler ödem tedavisinde intravitreal triamsinolon ve grid lazer fotokoagülasyon tedavisi görme keskinliğinin daha erken sürede artmasını sağlayabilmektedir ve maküla ödeminin tedavisinde etkin bir seçenektir.

J. Exp. Clin. Med., 2010; 27:152-156

\begin{abstract}
Retinal vein occlusion is the second most common retinal vascular disease after diabetic retinopathy. In this study, we investigate the effect of treatment of intravitreal triamsinolon with laser photocoagulation in eyes with macular edema after branch retinal vein occlusions (BRVO). Retrospective medical record review of 14 patients who underwent combine intravitreal triamcinolone acetonide enjection and grid laser photocoagulation for macular edema was conducted between October 2007 and February 2009. Macular edema was confirmed by fundus fluorescein angiography and optical coherence tomography. Patients received an intravitreal injection of $0.1 \mathrm{~mL}(4 \mathrm{mg})$ triamcinolone acetonide and grid laser photocoagulation was followed 1 month later. All of patients underwent a detailed ophthalmic examination included best corrected visual acuity, anterior and posterior segment biomicroscopy with a slit-lamp biomicroscopy, intraocular pressure. The mean age of the study patients was $56.3 \pm 7.3$ years. There were $11(79 \%)$ females and $3(21 \%)$ were males. A total of 8 of the study eyes $(57 \%)$ were superotemporal quadrant and 6 eyes (43\%) were inferotemporal quadrant. Visual acuity compared before treatment increased one or more line in $6 / 14$ patient $(43 \%)$ on third month, and $8 / 14$ patient $(57 \%)$ on six months. Visual acuity constant remained $4 / 14$ cases $(29 \%)$, and decreased one line only one patient $(7 \%)$ on follow-up time. During 6 months follow-up period glaucoma was occured in 3/14 patients $(21 \%)$, and cataract in one patient $(7 \%)$. As a result of the treatment of intravitreal triamcinolone and grid laser photocoagulation in eyes with macular edema after BRVO may be useful at the reduce of macular edema, and may increase visual acuity in the short term.
\end{abstract}

J. Exp. Clin. Med., 2010; 27:152-156

Bu çalışma 43. TOD Ulusal Kongresinde (Antalya 11-15 Kasım 2009) Poster olarak sunulmuştur.

(C) 2010 OMÜ Tüm Hakları Saklıdır. 


\section{Giriş}

Retinal vasküler tıkanıklıklar, diyabetik retinopatiden sonra en sık görülen görme azalması nedenidir. Retinal venöz tıkanıklığa bağlı görme azalması makülanın perfüzyon yetersizliği ve maküla ödemi nedenli olmaktadır (Rehak ve Rehak, 2008). Maküla ödeminin süresi ve şiddeti makülada dejeneratif değişikliklerin oluşumunda önemlidir ve görme prognozu ile yakından ilişkilidir.

Retinal ven dal tıkanıklığına (RVDT) bağlı görme azlığının en sık nedeni olan maküler ödem tedavisinde birçok tedavi uygulanmaktadır. Tedavide maküla ödemini azaltmak için; grid lazer fotokoagülasyon, intravitreal steroid, intravitreal anti-VEGF etkinliği çalıșmalarla gösterilmiş tedavi yöntemleridir( Rehak ve Rehak, 2008; Arnarsson ve Stefánsson, 2000). Arteriyovenöz ortak kılıfin diseksiyonu (Sheathotomy) bu olgularda uygulanılabilecek cerrahi seçenektir (Gürelik ve ark., 2003).

Çalışmamızda RVDT nedenli akut maküla ödemine bağlı görme azalması olan hastalar incelendi. Tüm hastalara intravitreal steroid ve bir ay sonra grid lazer fotokoagülasyon tedavisi uyguland 1 ve hastalarda erken dönemde görme keskinliğinde artı̧̧ elde edildi. Olguların tümünde tedavi öncesi floresein kaçağı ve maküler ödem olduğu görüldü. Tedaviden sonra ise tüm olgularda maküler ödemin gerildiği tespit edildi. Bu çalışma ile RVDT nedenli maküla ödemi olan hastalarda intravitreal steroid ve takiben bir ay sonra yapılacak grid lazer fotokagülasyon kombine tedavisinin etkin bir tedavi seçeneği olarak uygulanabileceği vurgulanmak istenmiştir.

\section{Gerec ve Yöntem}

Ondokuz Mayıs Üniversitesi Göz Hastalıkları Anabilim Dalı Retina biriminde takipli olan, ven dal t1kanıklığına bağlı maküla ödemi nedenli görme azalması olan 14 hastanın 14 gözü çalışmaya alındı. Görme azlığını hissetmeleri ile kliniğimize başvuru arasında geçen süre 2 ay altında olan hastalar çalışmaya alındı. Başvuru öncesi RVDT bağlı maküla ödemi nedenli herhangi bir tedavi almış olan hastalar çalıșmaya alınmadı.

Çalışmaya alınan hastaların Snellen eşeli ile en iyi düzeltilmiş görme keskinliği(EDGK), biyomikroskop ile ön ve arka segment muayenesi, Goldmann applanasyon tonometresi ile göz içi basınç ölçümü kayıt edildi. Fundus muayenesi ile tespit edilen maküler ödem fundus floresein anjiyografi (FFA) ve optik koherens tomografi (OKT) ile doğruland1.

Tüm hastalara ameliyathane şartlarında $\% 0,5$ proparakain hidroklorid (Alcaine $\left.{ }^{\circledR}\right)$ damla ile topikal anestezi uygulanarak \%5'lik povidon-iyodin ile oküler yüzey temizliği yapıldı. Alt temporalden limbusun $3,5 \mathrm{~mm}$ gerisinden 27 gauge iğne ile $4 \mathrm{mg}(0.1 \mathrm{~mL})$ triamsinolon (Kenakort-A $\left.{ }^{\circledR}\right)$ vitreus içine enjekte edildi. Enjeksiyon sonrası hastalara topikal fluorokinolon (Okacin $\left.{ }^{\circledR}\right) 4 \times 1$ bir hafta verildi. İntravitreal enjeksiyondan 1 ay sonra grid lazer fotokoagülasyon yapıldı.

Hastaların intravitreal enjeksiyondan 1 gün, 1 hafta, 1 ay, 3 ay ve 6 ay sonra detaylı göz muayeneleri yapıldı.
Maküler ödem takiplerde OKT ve FFA ile değerlendirildi. Görme keskinliği artışı (fonksiyonel başarı), maküler ödemde gerileme (anatomik başarı) ve komplikasyonlar kayıt edildi. Kontrollerde göz içi basıncı 21 mmHg'nin üzerinde olan olgulara topikal antiglokom tedavisi başlandi.

\section{Bulgular}

Çalıșma kapsamındaki 14 hastanın 11'i kadın, 3'ü erkekti. Hastaların yaş ortalaması 56,3 7,3 (41-66) idi. Olguların 8'inde (\%57) üst temporal, 6'sinda (\%43) alt temporal ven dal tıkanıklığı vardı. Hastaların görme azalmasını hissetmeleri ile ilk muayeneleri arasındaki süre 8 ile 54 gün arasında değişmekteydi (ortalama 29,7 gün). Olguların demografik ve klinik özellikleri Tablo'da sunulmuştur.

Hastalarda yapılan FFA tetkikinde olguların hepsinde makülada ödem olduğu ve tıkalı retinal ven alanında floresein kaçağı olduğu görüldü. Tedaviden 6 ay sonra yap1lan muayenede tüm olgularda maküla ödemin gerilediği tespit edildi. Maküler ödemde gerileme OKT ile de teyit edildi.

Tablo: Retinal ven dal tıkanıklığı nedenli tedavi yapılan hastaların demografik ve klinik özelliklerinin sunumu.

\begin{tabular}{|c|c|c|c|}
\hline Yaş & & $56.3 \pm 7.3$ & \\
\hline İlk başvuru zamanı (gün) & & $29,7 \pm 17$ & \\
\hline \multicolumn{4}{|l|}{ Cinsiyet n (\%) } \\
\hline Erkek & & $3(\% 21)$ & \\
\hline Kadın & & $11(\% 79)$ & \\
\hline \multicolumn{4}{|l|}{ Retinal tutulum n(\%) } \\
\hline Üst tempral & & $8(\% 57)$ & \\
\hline Alt temporal & & $6(\% 43)$ & \\
\hline \multicolumn{4}{|l|}{ Etkilenen göz n (\%) } \\
\hline Sağ & & $7(\% 50)$ & \\
\hline Sol & & $7(\% 50)$ & \\
\hline Tedavi ile Görme Keskinliği & n (\%) & 3. ay & 6. ay \\
\hline Artış & & $7(\% 50)$ & $8(\% 57)$ \\
\hline Azalma & & $1(\% 7)$ & $1(\% 7)$ \\
\hline Sabit kalma & & $6(\% 43)$ & $5(\% 36)$ \\
\hline
\end{tabular}

Üst temporal ven dal tıkanıklığına bağlı olarak sağ gözde görme keskinliği 0,4 Snellen düzeyinde olan 53 yaşındaki bayan hastanın tedavi öncesi ve tedavi sonrası fundus muayene bulguları ve OKT bulguları Şekil 1 (A-E)'de sunulmuştur. Olgunun sağ gözde görme keskinliği tedaviden 3 ay sonra 0,5 ve 6 ay sonra 0,7 Snellen düzeyindeydi.

Alt temporal ven dal tıkanıklığına bağlı olarak sağ gözde görme keskinliği 0,2 Snellen düzeyinde olan 57 yaşındaki bayan hastanın göz içi steroid ve grid lazer fotokoagülasyon tedavisi ile görmesi 3 . ayda 0,3 ve 6 . ayda 0,5 Snellen düzeyine çıktı. Bu olgunun tedavi öncesi ve sonrası OKT bulguları Şek. 2 (A-B)'de sunulmuştur.

Hastaların ilk başvurusunda Snellen eşeli ile yapılan en iyi düzeltilmiş görme keskinliği (EDGK) olguların $5 / 14$ ünde 0,05 ve altında, 5/14 ünde $0,1-0,2$ ve $4 / 14$ ünde 0,3 ve üzeri idi. İntravitreal steroid enjeksiyonu ve grid lazer fotokoagülasyon sonrası 3. ayda EDGK olguların 3/14 ünde 0,05 ve altında, $4 / 14$ ünde $0,1-0,2$ ve $7 / 14$ ünde 0,3 ve 

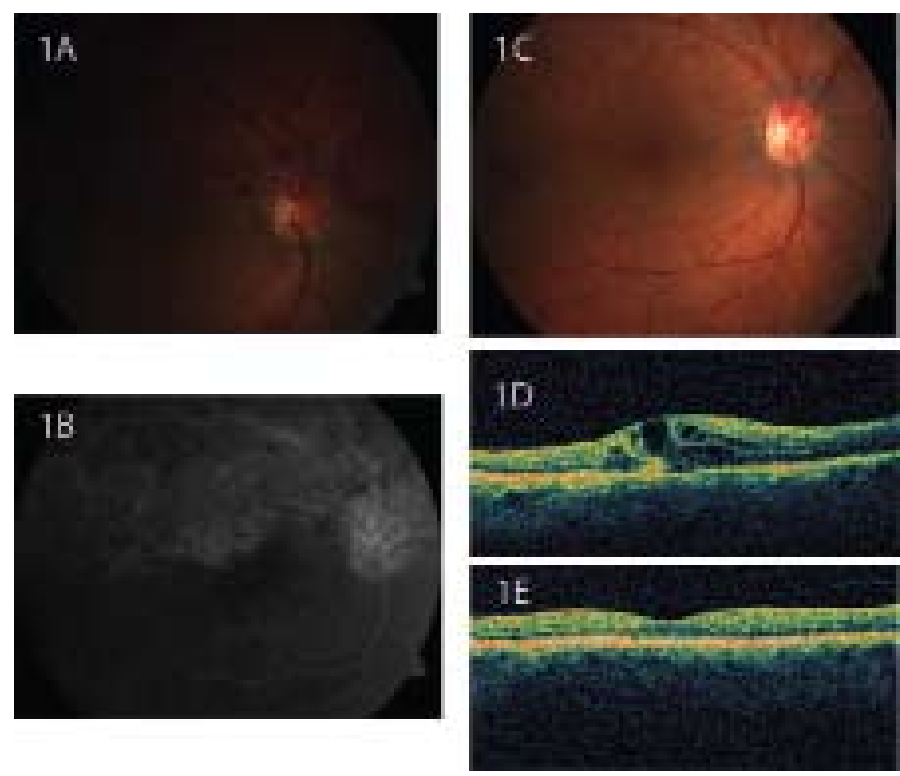

Şek. 1: Sağ gözde görme keskinliği ilk muayenesinde Snellen eșeli ile 0,4 olan bir olgunun (A) başvuru anında üst temporal retinada hemoraji olduğu, (B) fundus florosein anjiyografide üst yarı makülada ödem olduğu görüldü. (C) Tedaviden 6 ay sonra bu bölgedeki retinal ödemin gerilediği, hemorajilerin kaybolduğu ve lazer spotlarının olduğu görüldü. (D) Hastanın tedavi öncesi OKT ile görülen maküla ödeminin (E) tedaviden 6 ay sonra gerilediği, makülanın anatomik olarak normal olduğu görüldü.
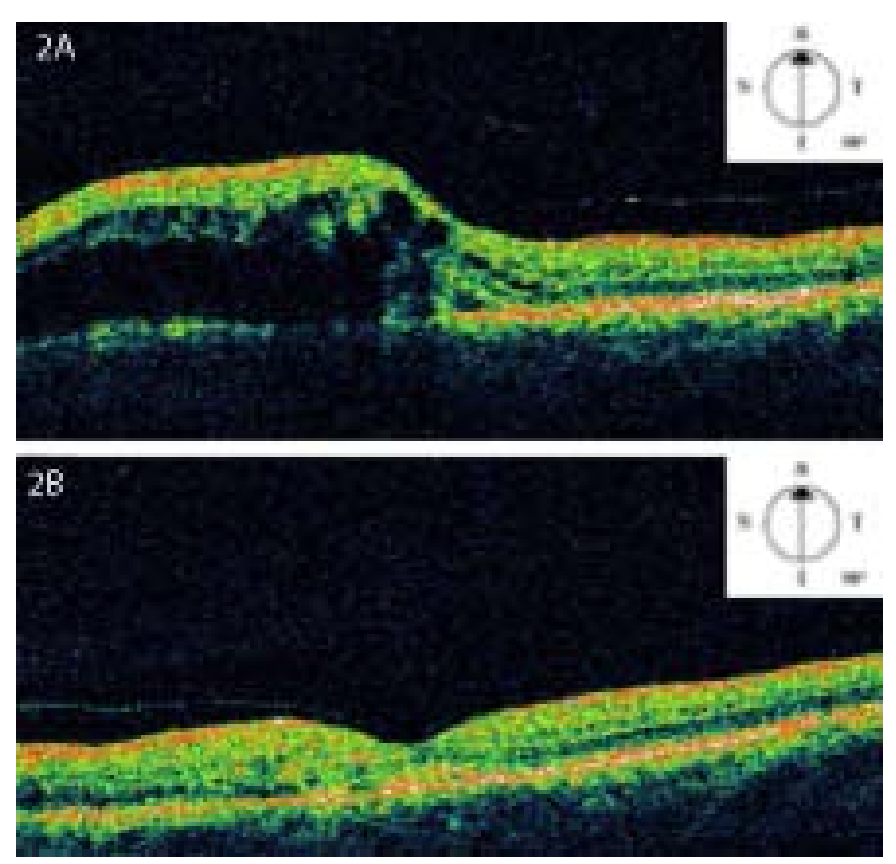

Şek. 2: Sağ gözde görme keskinliği başvuru anındaki ilk muayenesinde Snellen eşeli ile 0,2 olan olgunun OKT ile değerlendirmesi sunulmaktadır. (A) Hastanın başvuru anında makülanın alt yarısında ödemin olduğu görülmektedir. (B) Tedaviden altı ay sonraki OKT tetkikinde maküla ödeminin tamamen gerilediği, normal foveal çukurluğun oluştuğu görülmektedir.

üzerindeydi. Tedaviden 6 ay sonra yapılan kontrol muayenesinde EDGK olgularnn 3/14 ünde 0.05 ve altı, $3 / 14$ ünde $0,1-0,2$ ve $8 / 14$ ünde 0,3 ve üzerindeydi. Tedavi öncesine kıyasla EDGK değeri 3 . ayda $\% 43$ ve 6 . ayda $\% 57$ olguda bir sira ve üzerinde artt1. Sadece bir (\%7) olguda takip süresince görme düzeyi bir sıra azaldı. Olguların \%35'ine 6 ay sonunda görme keskinliği sabit kaldı. Tedavi sonrası 6 aylık takip süresinde olguların 3/14 ünde (\%21) glokom, 1 inde (\%7) katarakt gelişti. Hastaların görme keskinliğinin tedavi ile değişimi Şek. 3 'te gösterilmiştir.

\section{Tartışma}

Retinal ven dal tıkanıklı̆̆ının insidansı \%0,71,6'dır (Rehak ve Rehak, 2008). Retinal vasküler tıkanıklıklar diyabetik retinopatiden sonra en sık görme azalması nedendir. Hastalık etiyolojisinde başlıca retinal arteriol ve ven çapraz bölgesinde vende oluşan bası, damar duvarında dejeneratif değişiklikler ve hematolojik anormallikler yer almaktadır (Rehak ve Rehak, 2008). Bir gözünde retinal ven dal tıkanıklığı geçiren hastaların 4 yıl içinde diğer gözde de retinal venöz tıkanıklık geçirme ihtimali \%7'dir (Hayreh ve ark., 1990). Retinal venöz tıkanıklık yaklaşık 2/3 oranında üst temporalde, 1/3 oranında alt temporalde görülür (Hayreh ve ark., 1990). Nazal kadran etkilenimi, semptomların nadiren ortaya çıkmasından olsa gerek, çok daha az sıklıkla görülmektedir. Bizim olgularımızda da literatürle uyumlu olarak \%57 oranında üst temporal ven tıkanıklığı vard1.

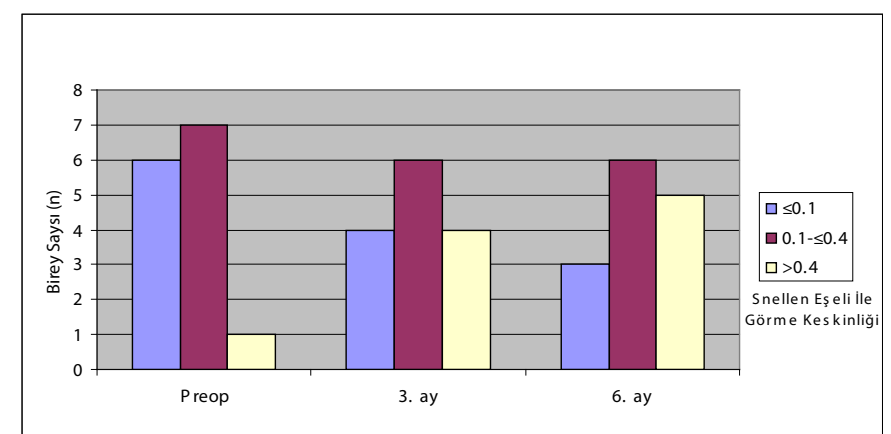

Şek. 3: Hastaların intravitreal steroid ve grid lazer fotokoagülasyon tedavisi öncesi ve tedaviden 3 ve 6 ay sonraki görme keskinliği sunulmuştur. Tedavi ile görmesi 0,1 ve altında olan olguların sayısı azalırken görmesi 0,4 üzerinde olan olgu sayısında artış olmuştur.

RVDT hastalara tedavi kararı verirken ve takipte fundus floresein anjiyografi (FFA) yapılmalıdır. Floresein anjiyografide makülanın perfüzyonu tedavi seçeneğinde etkili olacaktır. Maküla ödemini ve iskemi tespitinde FFA faydalıdır ancak retinal hemoraji varlığında bu etkisi azalacaktır. OCT bu durumlarda maküla ödemini tespit etmede faydalı olabilir. FFA ile değerlendirilen olgularda iskemik retinal alan 5 disk çapından büyük ise $\% 36$ oranında retinal neovaskülarizasyon görülmektedir (Tsaloumas ve ark., 2000). Biz göz içi enjeksiyon öncesi tüm hastalarda FFA ile maküla ödemi olduğunu tespit ettik. Bu olgularda maküla perfüzyonu vardı. Maküla ödemi olduğu OKT ile de doğruland1. Hiçbir olgumuzda FFA tetkikinde ödemi maskeleyecek hemoraji yoktu. Hastaların hiçbirinde 6 aylik takipte retinal neovaskülarizasyon görülmedi.

Retina ven dal tıkanıklığı olan hastalarda maküler ödem en önemli görme keskinliği azalma nedenidir. Maküla ödemi bu hastalarda kapiller endotelyal hücreler arasındaki sıkı bağlantıların tahrip olması ve vitreus ile retina arasında oluşan adezyonlar nedenli kan retina bariyerinin bozulmasına bağlı olarak retinada üretilen damar geçirgenliğini artıran maddelerin vitreusa salınması ile olur(Rehak ve Rehak, 2008). Tedavi öncesi görme keskinliği maküla perfüzyonunun değerlendirilmesi için iyi bir göstergedir. İlk muayene de iyi bir görme keskinliği prognozun iyi 
olacağının bir göstergesidir. Maküla ödemi nedenli görme azlığ oluşan RVDT hastalarında tedavide amaç, spontan olarak maküla ödemi düzelmeyen olgularda maküla ödeminin gerileme süresinin kısaltılması ile ödeme bağlı fotoreseptör tahribatının önlenmesidir (Rehak ve Rehak, 2008). Final görme keskinliği hiçbir tedavi uygulanmasa da olguların \%50-60'ında 20/40 ve üzerinde olmaktadır (Rehak ve Rehak, 2008).

Grid lazer fotokoagülasyon tedavisi RVDT nedenli maküla ödemi tedavisinde etkinliği gösterilmiş önemli bir tedavi seçeneğidir. Maküla ödeminde lazer tedavisi retinal oksijenizasyonu artırıcı etkisi ile maküla ödemini azaltmaktadır (Arnarsson ve Stefánsson, 2000). Artmış oksijenizasyon ile damarlarda daralma ve kisalmaya neden olmakta, intravasküler basınçta düşmeye neden olmakta ve Starlin kuralına göre maküla ödeminde gerilemeye neden olmaktadır (Arnarsson ve Stefánsson, 2000). Prospektif olarak yapılan "Branch vein occlusion study group" çalışmasında erken dönem RVDT olan, perfüze maküla ödemi olan, foveal hemorajisi olmayan, görme keskinliği 20/40 ya da daha az olan ve başka bir göz hastalığı olmayan olgularda grid lazer tedavi etkinliği değerlendirilmiş (Branch Vein Occlusion Study Group, 1998). Bu çalışmada üç yıl sonra tedavi öncesine göre grid lazer fotokoagülasyon tedavisi uygulanan olgularda $\% 65$, tedavi yapılmayan olgularda ise $\% 37$ oranında 2 sira ya da daha üzerinde görme keskinliği artışı elde edilmiş. Bu iki grup arasında görme keskinliğinde 2 sıra ve üzerinde azalma olan olgular istatistiksel olarak anlamlı değilmiş.

Kortikosteroidler araşidonik asit yolunun inhibisyonu özelliği ile maküla ödemi gerilemesinde kullanılmaktadır. Bu etki ile vasküler büyüme faktörü sentezini azaltmaktadırlar. Hücreler arası adezyon molekülleri sentezini ve retina pigment epiteli bariyer fonksiyonunu düzenleyerek ödemin gerilemesine katkı sağlamaktadır (Karaçorlu ve ark., 2005). Göz içi steroid enjeksiyonu ile RVDT bağlı maküla ödeminde hızlı bir gerileme olmaktadır. Fakat steroid enjeksiyonu ile elde edilen maküla ödemindeki gerileme geçicidir (Cakir ve ark., 2008). Grid lazer tedavisi ya da hiçbir tedavi yapılmayan olgulardan oluşan kontrol grubu ile göz içi steroid enjeksiyonu yapılan çalışma grubu olguların karşılaştırıldığ 27 hastadan oluşan çalışmada, göz içi steroid kullanımı ile kontrol grubuna göre maküla ödeminin gerilemesi ve görme keskinliği artışının istatistiksel olarak anlamlı farklı olduğu bulunmuştur (Cheng ve Wu, 2006). Ülkemizde yapılan bir çalışmada RVDT bağlı maküla ödeminde göz içi steroid enjeksiyon tedavisi yapılan çalışma grubu ile tedavisiz olgulardan oluşan kontrol grubunda görme keskinliği artışı ve maküla ödemindeki gerileme değerlendirilmiş, tedavi yapılan grupta istatistiksel olarak anlamlı düzelme olduğunu bulunmuştur (Çekiç ve ark., 2005). İntravitreal steroidlerin göz içi basınç artış1 ve katarakt en s1k görülen yan etkileri tedavide olabilecek yan etkilerdendir.

Retinal ven dal tıkanıklığına bağlı maküla ödeminde grid lazer tedavisi eğer FFA da maküler perfüzyon yoksa yapılmamalıdır (Branch Vein Occlusion Study Group, 1998). Grid lazer tedavisi ile özellikle maküla ödemine bağl1 görme düzeyi 20/40 ve altında olan RVDT olgularında tedavi başarısı yüksek iken görme düzeyi iyi olan olgularda bu etki azalmakta hatta tedavi yapılmayan kontrol grubuna göre benzer başarı oranları elde edilmektedir (Branch Vein Occlusion Study Group, 1998). İntravitreal steroidler RVDT nedenli maküla ödeminde hızlı bir maküla ödemi regresyonu sağlamakta fakat bu etki kısa süreli olmakta, bu nedenle tekrarlayan enjeksiyonlar gerekebilmektedir (Çekiç ve ark., 2005). Bu veriler 1şı̆̆ında RVDT bağlı maküla ödeminde intravitreal steroid ve grid lazer fotokoagülasyon tedavisi bu olgularda başarı oranını artırabilir. 63 olguda grid lazer, göz içi steroid ve her iki tedavinin kombine uygulandığ 3 farklı tedavi grubundan oluşan bir çalışmada, kombine tedavi uygulanan grupta görme keskinliği düzelme oranının daha yüksek olduğu tespit edilmiş (Avitabile ve ark., 2005). Bizim tedavi protokolümüze benzer olarak yapılan bir çalışmada RVDT nedenli persistan maküla ödemi olan (15/24 non-iskemik, 9/24 iskemik) olgularda yapılmış (Reise ve ark., 2008). Bu çalışmada olguların tedavi öncesine kıyasla kombine intravitreal steroid ve grid tedavisinden altı ay sonraki değerlendirmede belirgin santral maküla kalınlığında gerileme ve görme keskinliği artışı elde edilmiştir.

Retinal ven dal tıkanıklığına bağlı maküla ödeminde intravitreal vasküler endotelyal büyüme faktörü (VEGF) inhibitörleri de kullanılmaktadır (Eken ve ark, 2009). Bu amaçla ülkemizde yayınlanan RVDT olguları üzerinde göz içi steroid enjeksiyonu ve göz içi anti-VEGF (bevacizumab) enjeksiyonu tedavi sonuçlarını karşılaştıran bir çalışmada her iki uygulamada da benzer görme keskinliği artışı elde edilmiştir (Akıncı ve ark., 2009). Yine bu çalışmada göz içi steroid uygulanan grupta daha fazla intraoküler komplikasyona rastlanılmıştır.

Bizim çalışmamız kontrol grubu olmayan ve RVDT nedenli maküla ödemi olan intravitreal steroid ve grid lazer fotokoagülasyon kombine tedavisi uygulanan 14 olgunun 14 gözünden oluşmaktadır. Altı ay sonunda başlangıç görme düzeyine kıyasla \%57 (8/14) oranında görme keskinliği artışı elde edildi. Olguların tümünde altı ay sonunda maküla ödemi gerilemişti. Kombine tedavi ile RVDT nedenli maküla ödemi olan olgularda başarılı sonuçlar elde edilebilir ve tedavi etkinliği tek başına uygulanacak grid lazer ya da intravitreal steroid tedaviye göre daha etkin olabilmektedir.

\section{KAYNAKLAR:}

Akıncı, A., Bilen, Ö., Elmas, K., Altınsoy, A., 2009. Retina Ven Dal Tıkanıklı̆ı̆ına Bağlı Makula Ödemi Tedavisinde İntravitreal Bevacizumab ve Triamsinolon Acetonidin Karşılaştırılması. Ret-Vit. 17, 48-50.

Arnarsson, A., Stefánsson, E., 2000. Laser treatment and the mechanism of edema reduction in branch retinal vein occlusion. Invest Ophthalmol Vis Sci. 41, 877-79.

Avitabile, T., Longo, A., Reibaldi, A., 2005. Intravitreal triamcinolone compared with macular laser grid photocoagulation for the 
treatment of cystoidmacular edema. Am. J. Ophthalmol. 140, 695-702.

Branch Vein Occlusion Study Group. 1986. Argon laser scatter photocoagulation for prevention of neovascularization and hemorrhage in branch vein occlusion. Arch. Ophthalmol. 104, 34-41.

Cakir, M., Dogan, M., Bayraktar, Z., Bayraktar, S., Acar, N., Altan, T., Kapran, Z., Yilmaz, O.F., 2008. Efficacy of intravitreal triamcinolone for the treatment of macular edema secondary to branch retinal vein occlusion in eyes with or without grid laser photocoagulation. Retina. 28, 465-472.

Cekic, O., Chang, S., Tseng, J.J., Barile, G.R., Del Priore, L.V., Weissman, H., Schiff, W.M., Ober, M.D., 2005. Intravitreal triamcinolone injection for treatment ofmacular edema secondary to branch retinal vein occlusion. Retina. 25, 851-855.

Cheng, K.C., Wu, W.C., 2006. Intravitreal triamcinolone acetonide for patients with macular edema due to branch retinal vein occlusion. Kaohsiung J. Med. Sci. 22, 321-330.

Eken, V., Batıoğlu, F., Özmert, E., Duman, R., 2009. Retina Ven Tıkanıklığına Bağlı Makula Ödeminin Tedavisinde İntravitreal Bevacizumab (Avastinß) Enjeksiyonunun Etkinliği. Ret-Vit. 17, 171-175.

Gürelik, G., Özdek, Ş., Aydın, B., Konuk, O., Hasanreisoğlu B., 2003.Retinal ven dal tıkanıklı̆̆ı tedavisinde arteriyovenöz kılıf dekompresyonu. Ret-Vit. 11, 47-53.

Hayreh, S.S., Zimmerman, B., Podhajsky, P., 1990. Incidence of various types of retinal vein occlusion and their recurrence and demographic characteristics. Am. J. Ophthalmol. 117, 429-441.

Karaçorlu, S.A., Karaçorlu, M., Özdemir, H., 2005. Retina ven dal tıkanıklığında intravitreal triamsinolon asetonid tedavisi sonrası maküladaki değişikliklerin incelenmesi. Ret-Vit. 13, 273-277.

Rehak, J., Rehak, M., 2008. Branch retinal vein occlusion: pathogenesis, visual prognosis, and treatment modalities. Curr Eye Res. 33, 111-131.

Reise, J., Loukopoulos, V., Meier, C., Timmermann, M., Gerding, H., 2008. Combined intravitreal triamcinolone injection and laser photocoagulation in eyes with persistent macular edema after branch retinal vein occlusion. Graefes Arch. Clin. Exp. Ophthalmol. 246, 1671-1676.

Tsaloumas, M.D., Kirwan, J., Vinall, H., O’Leary, M.B., Prior, P., Kritzinger, E.E., Dodson, P.M., 2000. Nine year follow-up study of morbidity and mortality in retinal vein occlusion. Eye. 14, 821-827. 